\title{
EL PENDULO DE FOUCAULT \\ La gran novela de la Postmodernidad
}

\section{Blanca Inés Gómez de González *}

Me estaba preguntando quiénes somos nosotros. Nosotros, que pensamos que Hamlet es más real que el portero de nuestra casa"

El Péndulo de Foucault. (307).

El final del milenio parece anunciarse con una profunda revisión crítica. Los libros recién publicados clausuran el desencanto de una etapa de la humanidad y anticipan, de otro lado, las características de lo que habrá de ser la literatura del próximo milenio ${ }^{1}$.

Dos escritores italianos Umberto Eco e Italo Calvino hacen el balance final de las conquistas más significativas de estos diez siglos; el devenir de la racionalidad como fundamento del humanismo y la difusión del libro, en un milenio testigo del desarrollo de la expresión literaria de las lenguas occidentales.

Mientras el desencanto de la racionalidad lleva a Eco al encuentro con el hermetismo, ese mismo desencanto en Calvino parece hablar de la necesidad de aligerar el pensamiento. En su postulado frente a la pesadez del diario vivir la literatura se abre como puerta infinita que nos lleva a explorar para construir una nueva imagen del mundo.

La actitud ética de la postmodernidad centra la reflexión en el desencanto de lo aparente, de lo insostenible, como ya lo había anunciado Kundera y como lo reafima Eco "La verdad es brevísima el resto, sólo es comentario" (El péndulo. 571), a la pesadez del mundo se opone la libertad que el hombre obtiene del verdadero conocimiento.

Son esas precisamente las reflexiones finales de Casaubon, el narrador del Péndulo. Me duele pensar que no volveré a ver a Lía y al niño la Cosa. Giulio, mi piedra filosofal. Pero las piedras sobreviven por sí solas. Quizá ahora esté viviendo su ocasión. Ha encontrado una pelota, una homiga, una brizna de hierba, y en ellas está contem plando una imagen en abyme del paraíso

También él lo sabrá demasiado tarde. Estará bien que agote así por sí solo, su jornada (579).

\footnotetext{
*Profesora de Literatura. Universidad Pedagógica Nacional.

1 Calvino, Italo. Seis propuestas para el próximo milenio. Barcelona: Ediciones Siruela, 1989.
} 
A esta imagen de Sísifo que lleva sobre sus hombros la pesada piedra, Calvino contrapone la imagen de Pérgamo que avanza con sus sandalias aladas.

Pocos libros han sido esperados con tanto interés por sus lectores como la última novela de Umberto Eco: El Péndulo de Foucault; escrito tras largo y consciente proceso de investigación, después del éxito de su primer best seller $E$ nombre de la Rosa.

El lector de Eco sabe que ha de entrar en el texto con mirada inquisidora para participar activamente en la creación del texto concebido ya, a su entender, como una máquina para producir chis pas de sentido.

En él la forma novelesca se constituye no solo en un acerbo de conocimientos, o en un microcosmos del mundo, sino en una intrincada red donde interactúan múltiples sistemas. "La novela contemporánea es enciclopedia, método de conocimiento y sobre todo red de conexiones entre los hechos, entre las personas, entre las cosas del mundo" (Calvino. 121). La novela de hoy postula por tanto una nueva mirada, sobre el mundo y su historia caracterizada por la ironía. No en vano, el texto buscado en El Nombre de la Rosa había sido el libro II de la Poética de Aristóteles. El libro de la comedia, o del mundo del carnaval y de la sátira. Con lo cual Eco apunta a un nuevo nivel de lectura, la lectura del crítico familiarizado con las teorías de Bajtín sobre la carnavalización del mundo y la plasmación de un espacio donde es posible revelar un sin fin de virtualidades.

Recordemos como para Eco, la novela surge de la posibilidad de mentir y de la posibilidad de reír, características exclusivas del hombre. Eco sostiene que la semiótica es una teoría de la mentira, y por lo tanto un texto es siempre una mentira y su fuerza máxima es la risa.

El humor entendido como lo cómico que ha perdido la pesadez corpórea, articula la novela de un semiólogo que explota en ella el filón más rico en la interpretación simbólica: el pensamiento hermético; para satirizar la estulticia y la locura humanas base del sin sentido de la racionalidad de la lógica occidental.

Para el hermetismo "desde cierto punto de vis ta en este mundo todo tiene que ver con todo" (283) y "no existe en el universo algún dato que no revele algo distinto" (336); este postulado va a ser parodiado y glosado infinitamente por la novela, inscrita en el más negro humor de nuestros tiempos: la obra cinematográfica de Woody Allen. Con ello se logra el efecto contrario de la lectura única, postulada como la lectura modelo de Guillemo de Basquerville en El nombre de la rosa.

En efecto, silo asombroso de la lectura del investigador radicaba en la lectura de los signos como impronta o huella de la realidad, los lectores de signos, tres intelectuales (Casaubon, Belbo y Diotallevi) en El péndulo de Foucault, tejen una trama engañosa que los encierra hasta exterminarlos, pues su lectura se opone a la certeza de la lectura de Guillemo de Basquerville en El nombre de la rosa; lectura que, en esta obra, será suplantada por la de la conjetura y la sospecha. 
De allí que la lectura de los intelectuales sea una lectura virtual que debe ser reordenada por el lector ideal Casaubon, como narrador y recopilador final; su lectura como lectura ideal pasa a través del filtro de Abulafia que no es otra cosa que el corrector de estilo de la moderna tecnología.

Como en El nombre de la rosa la novela resulta ser un manuscrito, pero a la manera modema es un diskete que debe ser operado a partir de la palabra clave. Si Adso escribe su manuscrito a finales del siglo XIV, Belbo deja su manuscrito en el procesador de palabras a finales del siglo XX; una y otra novela resultan ser producto de una mediación: Umberto Eco retoma el manuscrito de Adso, Casaubon, el de Belbo.

Mediación que siempre lleva a la sospecha de una existencia anterior. Lo que hilvana la novela es el problema de la semiosis ilimitada como base existencial de la cultura: todo signo es el interpretante de otros signos y todo signo interpretante es interpretado a su vez.

Desde este punto de vista la historia de la humanidad no ha sido otra cosa que la búsqueda infructuosa del secreto de los templarios; comunidad religiosa que se dispersa por el mundo a partir del año de 1307. El autor ha regresado al siglo de su predilección. Eco situaba la acción de El nombre de la rosa en 1327, en una abadía benedictina. El péndulo de Foucault es también una novela histórica que se acoge a los hitos de la postmodernidad.

En ella el pasado regresa continuamente no para narrarlo sino para hacerlo entrar en relación con el presente, "su herencia no se conserva solamente mediante la hibemación, sino mediante nuevas y continuas traducciones y utilizaciones"

Este reciclaje continuo del pasado es una exigencia del desencanto de la postmodemidad "Las utopías del mundo modemo han fracasado, los tiempos están maduros para la revalorización de la cultura de lo inactual (El péndulo. 232).

La ironía es la óptica recurrente de Eco en sus obras, si la una narra el acceso a la modernidad y se centra en la controversia del nominalismo de Guillemo de Ocam para denotar el paso de la creencia a la sospecha, abriendo un abismo entre verdad y certeza. La nueva novela de Eco postula cómo la ciencia al convertirse en una nueva religión tiende sobre nosotros un nuevo manto de sombra.

La obra así entendida, resulta ser la gran novela de la postmodernidad. Eco ha vuelto a visitar el pasado con ironía, sin ingenuidad, para volver a contar la historia que, de alguna manera, es también nuestro presente: "¿Por qué escribir novelas? Se pregunta Belbo- Reescribir la historia. La historia en la cual luego te conviertes" (El péndulo. 479).

${ }^{2}$ Eco, Umberto. La nueva edad media. Madrid: Alianza, 1984, p. 34. 
En ella el mundo vuelve a ser la gran metáfora de la locura como en la obra de Erasmo y sus personajes, a fin de no zozobrar, se embarcan en la nave de los locos. Los pasajeros de esta barca de carnaval pueden muy bien cantar, como los de Brandt: "Erramos en busca de puertos y de orillas y jamás podremos tocar tierras; nuestros viajes no tienen fin, pues nadie sabe dónde abordar y así el descanso huye de nosotros día y noche".

Para Eco la gran locura del hombre es la estulticia de Erasmo y por eso el móvil de la historia no ha sido otro que la búsqueda de un secreto inexistente. Esta ha sido la gran estupidez del hombre; "en el mundo, están los cretinos, los imbéciles, los estúpidos y los locos. En suma todo el mundo, si se mira bien, participa de alguna de esas categorías" (El péndulo .60). Entre ellas la estupidez ha sido la base de la lógica occidental, "el estúpido se equivoca de razonamiento", el intento de Eco es demostrar las falacias de las filosofías para señalar como la plenitud del conocimiento se encuentra en el hallazgo personal.

Las novelas de Eco son palimpsestos, manuscritos que conservan la huella de una escritura anterior. El gran cetón de El nombre de rosa es la Biblia. En El péndulo de Foucault el diálogo intertextual se extiende a la tradición heméticocabalística; la novela rees cribe la historia del hemetismo a la vez que reinterpreta la historia des de el hemetismo. El esoterismo vis to como una antiquísima cantera que partiendo del antiguo Egipto con Hermes Trismegis to (¿o del siglo II?) retorna en el Renacimiento, para volver a llevar la magia a una nueva edad de oro, renace con los cabalistas para llegar hasta el siglo XIX con el ocultismo, y se hace vigente aun en la masonería, se constituye en el subtexto de la obra.

El milenarismo del año 2000 abre de nuevo las compuertas a la magia y al esoterismo. Los intelectuales que trabajan en la editorial de Milán repiten la historia de la Florencia del siglo XV cuando Ficino traduce el Asclepius. En este nivel de lectura la novela se entronca con las investigaciones de Frances Yates, sobre el arte de la memoria y la tradición hemética.

Textos que de otra parte ya habían alimentado la imaginación de Carlos Fuentes en Terra Nostra, donde se crea un mundo totalizante al posibilitar una lectura en abismo, lectura cabalística de un texto único que alberga todos los textos posibles. Alí el simultaneísmo partía de la actualización del teatro de la memoria del divino Camilo del siglo XV, y en él la mnemotecnia tenía un carácter mágico; en El péndulo de Foucault, Giulio Camilo como el Ireneo Funes de Borges adolece de la capacidad de olvidar y la memoria como mnemotecnia de los loci (lugares) da pie para una nueva lectura del secreto de las Pirámides donde se demuestra, en uno de los episodios más relevantes de la obra: la gratuidad de la numerología. Las analogías entre estas dos novelas capitales en este final de siglo van más allá, las dos son novelas apocalípticas y milenaristas y en ambas la cábala hace posible la actualización del mundo novelesco. 
El Péndulo de Foucault se estructura en diez capítulos que recuerdan los diez sefiroth de la divinidad, o emanaciones de la inteligencia infinita, el soph, el ser primordial. Los sefiroth corresponden a los dedos de la mano y emanan uno de otro. La primera emanación es la corona y de ella emanan las otras. Para los cabalistas el nombre de Dios es secreto y si alguien llegara al tetragramaton -el nombre de cuatro letras de Dios- y supiera pronunciarlo correctamente, podría crear un mundo. Las letras por tanto se constituyen en una escritura sagrada, en un criptograma que es necesario descifrar. "La letras fundamentales son veintidós y con ellas, sólo con ellas, Dios fomó toda la creación. (El péndulo. 36).

El hombre debe hallar la palabra clave para poder regresar a la divinidad, a través de la cábala "cuando el hombre quiere dirigir una plegaria al Señor, puede invocar igualmente, ora los nombres de Dios, Eheleh, Jah, Johován, El, Elohim, Jedud, Elohei, Isabaoth, Schadai, Adonai, ora los diez Sephiroth, a saber: la corona, la sabiduría, la inteligencia, la belleza, la gracia, la justicia" ${ }^{3}$ Los diez Sefiroth y los nombres de Dios son una sola y la misma cosa.

Pero el hombre ha perdido el omphalos, el centro; en tanto que los símbolos en El nombre de la rosa llevaban al conocimiento de la realidad, aquí no son otra cosa que el alejamiento del centro, del infinito y de la verdad, simbólicamente expresados en El péndulo, que os cila entre la racionalidad y el deseo 4 .

La historia, parece decimos Eco, solo construye redes que destruyen el anhelo del conocimiento del hombre. Recordemos la historia del golem en la conferencia sobre la Cábala de Borges ${ }^{5}$.

"Se supone que si un rabino aprende o llega a descubrir el secreto nombre de Dios y lo pronuncia sobre una figura humana hecha de arcilla, esta se anima y se llama golem. En una de las versiones de la leyenda, se inscribe en la frente del golem la palabra EMT, que significa verdad. El golem crece, hay un momento en que es tan alto que su dueño no puede alcanzarlo. Le pide que le ate los zapatos, el golem se inclina y el rabino sopla y logra borrarle el aleph o primera letra de Emet. Queda MET, muerte. El golem se transforma en polvo".

\footnotetext{
${ }_{4}^{3}$ Franck A. La Kabbala. Madrid: Editorial humanistas.1983, p. 85

4 Esto podría explicar el nuevo tratamiento del erotismo que se expresa simbólicamente en el objeto del deseo, la trompeta; en tanto que la mujer Lía es la mujer práctica de Jacob, tal corno lo alude en la referencia al Cap. XXVII del purgatorio de la Divina Comedia (Péndulo 205). La Novela de Eco es profundamente intelectual, recordemos cómo en el Nombre de la Rosa, la experiencia erótica de Adso era una recuperación del Cantar de los cantares.
}

${ }^{5}$ La cábala en Siete noches. Méjico: Fondo de Cultura Económica. 1980, p. 139. 